Obere Extremität 2019 $\cdot 14: 256-262$

https://doi.org/10.1007/s11678-019-0523-3

Received: 7 January 2019

Accepted: 10 May 2019

Published online: 6 June 2019

(c) The Author(s) 2019

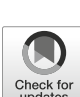

\author{
Alexander Ellwein ${ }^{1,2} \cdot$ Helmut Lill ${ }^{2}$ Tomas Smith ${ }^{1} \cdot$ Christine Voigt ${ }^{2}$. \\ Julia Imrecke ${ }^{2}$. Jan Christoph Katthagen ${ }^{3}$ \\ 'Department for Orthopaedic Surgery, Medical School Hannover, DIAKOVERE Annastift, Hannover, \\ Germany \\ ${ }^{2}$ Department for Orthopaedic Surgery and Traumatology, DIAKOVERE Friederikenstift, Hannover, Germany \\ ${ }^{3}$ Department for Traumatology, Hand and Reconstructive Surgery, University Hospital Münster, Muenster, \\ Germany
}

\section{Primary vs. secondary total elbow arthroplasty for distal humerus fractures}

\section{Clinical results of a retrospective case-control study}

after TEA are mostly good to excellent [6, $8-16]$, but weight-bearing is limited to a maximum of $5 \mathrm{~kg}$ lifelong, and the longterm implant survival is as yet unknown [17]. When comparing reconstruction and primary TEA as treatment for distal humerus fractures, the functional results are similar but the risk of a major complication such as implant failure, infection, or nerve lesion increases 4.4 -fold after open reduction and internal fixation [18]. Further investigations are needed to clarify whether TEA after failed nonoperative treatment or open reduction and internal fixation provides the same results as primary TEA.

The aim of this study was to compare functional results and complication rates after primary TEA and TEA after failed reconstruction or conservative treatment in distal humerus fractures. We hypothesized that clinical and functional results are better with primary TEA and that primary TEA leads to fewer complications.

\section{Methods}

The main goal of distal humeral fracture treatment is anatomic reconstruction with preservation of the elbow joint. Total elbow arthroplasty represents an alternative treatment option providing immediate pain relief with a stable and functional elbow $[6,7]$. The functional results about the study and provided written informed consent.

\section{Patients}

All patients undergoing TEA were identified by electronically screening our database for cases of linked and unlinked TEA between August 2008 and and radiographs, the indication for implantation in TEA was retrospectively reviewed. All patients who underwent TEA for an acute trauma with fracture of the distal humerus (primary TEA; - Fig. 1) or for failed reconstruction or nonoperative treatment after a distal humerus fracture (secondary TEA; - Fig. 2) were included in this study. A minimum follow-up of 6 months was set as the inclusion criterion. Exclusion criteria were previous injury at the fractured elbow, neuromuscular disease, cortisone or other immune-suppressive therapy, and an open fracture of grade II or higher according to the Tscherne and Ostern classification [19]. After excluding one patient because of preexisting hemiplegia of the affected arm, 35 patients met the inclusion criteria. The patient records were reviewed for demographic and perioperative data. If the initial treatment was not conducted May 2014. On the basis of patient records
This retrospective study was performed at a level I trauma center. The study protocol was reviewed and approved by the local ethics committee and complied of Helsinki. All patients were informed with the principles of the Declaration 

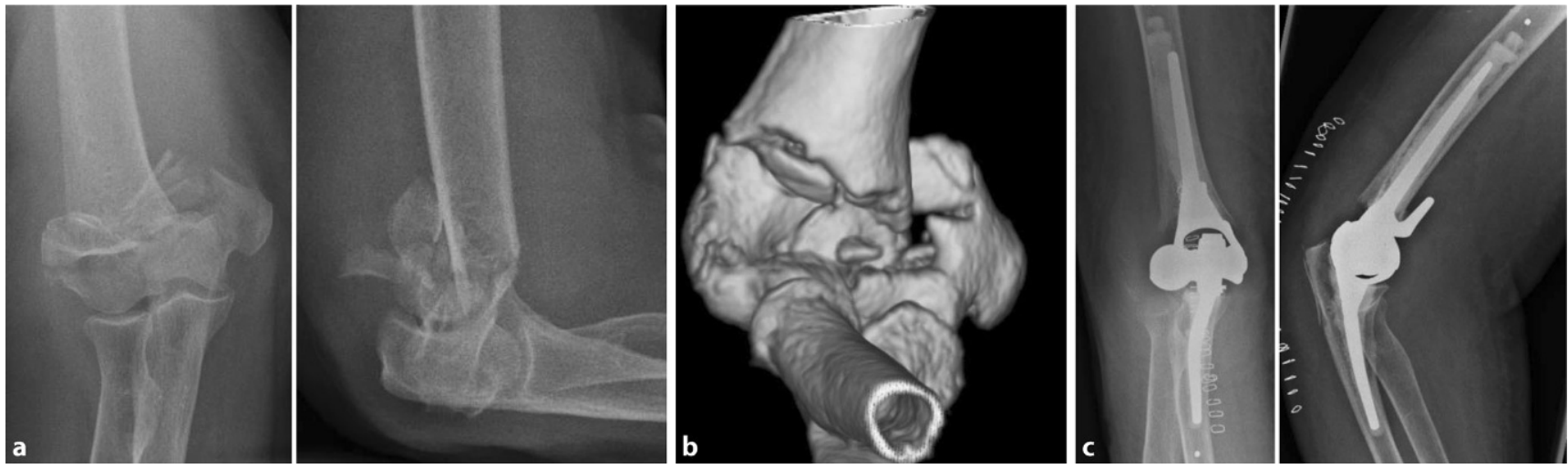

Fig. 1 A Primary total elbow arthroplasty in a 74-year-old woman with distal humeral fracture, AO type C3:a multifragmentary intra-articular fracture; $\mathbf{b} 3 \mathrm{D}$ reconstruction of the computed tomography scan; $\mathbf{c}$ implant in total elbow arthroplasty
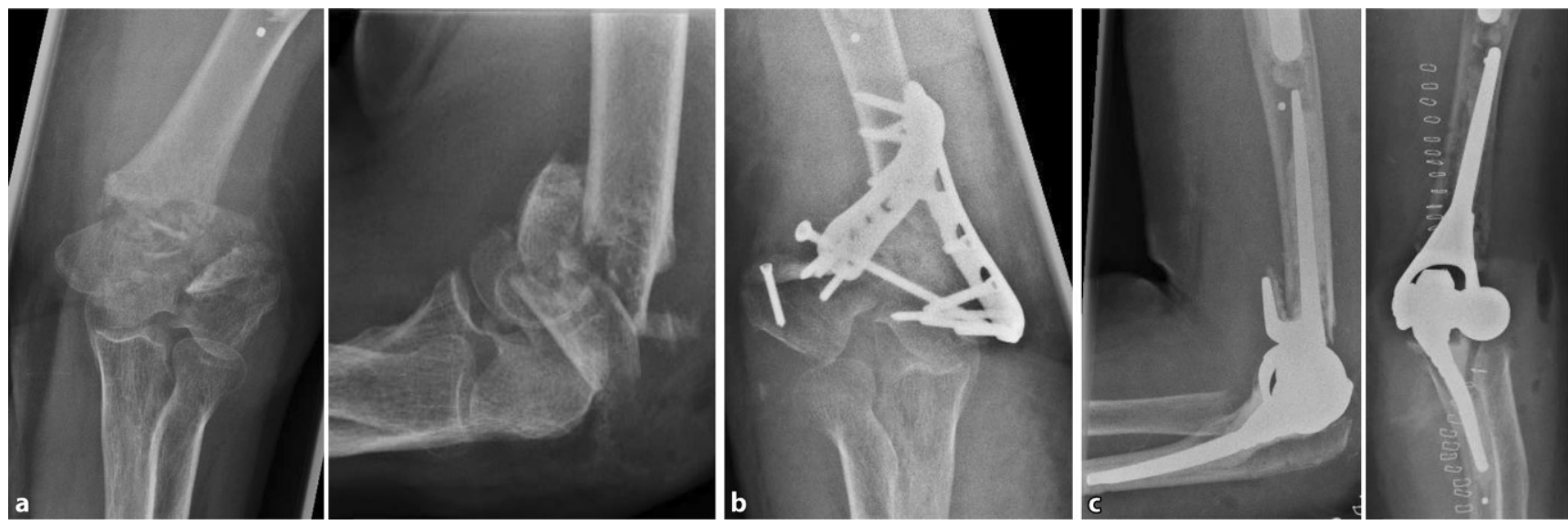

Fig. 2 \ Secondary total elbow arthroplasty in an 82-year-old woman with distal humeral fracture, AO type C2: a complete intra-articular fracture with metaphyseal comminution; $\mathbf{b}$ loss of reduction after 5 days; c implant in total elbow arthroplasty

in our department, radiographs and patient records were requested.

\section{Procedure}

All patients received a semiconstrained, cemented total elbow prosthesis (Latitude, Tornier, Bloomington, IN, USA), which was implanted using a modified Campbell approach. The posterior split of the triceps muscle in the midline was extended to the proximal ulna with a radial and ulnar periosteal flap. The ulnar nerve was exposed in all cases. Transposition of the nerve was necessary in four cases after secondary TEA. Postoperatively, all patients were treated according to a standardized protocol. After 2 days of immobilization and radiological assessment, early functional treatment was started to prevent elbow stiffness [20], as even a small loss of motion can substantially reduce the patient's quality of life [21]. Owing to the extended approach, elbow flexion was limited to $90^{\circ}$ for 6 weeks. Weight-bearing was not allowed for the same time.

All patients were invited to a onetime follow-up examination, which included evaluation of range of motion and stability of the elbow, actual pain assessed via the Visual Analog Scale for Pain (VAS), and patient satisfaction (satisfied vs. dissatisfied). To objectify the functional result, the Mayo Elbow Performance Score (MEPS) and Disabilities of the Arm, Shoulder and Hand Score (DASH) were analyzed. Additionally, complications and revision surgeries were recorded. Complications were categorized as minor (nerve irritation or postoperative hematoma) and major (those that required a revision of the prosthesis). Postoperative radiographs of all patients and further follow-up radiographs, if available, were analyzed.

\section{Statistical analysis}

Perioperative data, functional results (range of motion and MEPS and DASH scores), and postoperative complications were described for each group. Subsequently, these results were statistically compared using the Mann-Whitney $U$ test as a two-way analysis of variance for independent factors. A $p$ value of $\leq 0.05$ was considered statistically significant. Since the study was purely exploratory in design, and only a small group of patients was compared, the $p$ values reported can be interpreted only descriptively. All statistical analyses were performed using SPSS for Mac (IBM SPSS Statistics 22, Chicago, IL, USA). 
Obere Extremität 2019 · 14:256-262 https://doi.org/10.1007/s11678-019-0523-3

(c) The Author(s) 2019

A. Ellwein · H. Lill · T. Smith · C. Voigt · J. Imrecke · J. C. Katthagen

\section{Primary vs. secondary total elbow arthroplasty for distal humerus fractures. Clinical results of a retrospective case-control study}

\section{Abstract}

Background. The purpose of this study was to compare functional results and complication rates after primary total elbow arthroplasty (TEA) and TEA after failed reconstruction or nonoperative treatment (secondary TEA) for distal humerus fractures. We hypothesized that clinical and functional results are better for primary TEA with fewer complications. Patients and methods. Data of 23 patients (primary TEA, $n=9$; secondary TEA, $n=14$; mean age, 66 years) were retrospectively reviewed with a mean follow-up of 28 months (range, 6-43 months). The clinical and functional results were evaluated using the arc of motion, Mayo Elbow Performance Score
(MEPS), and Disabilities of the Arm, Shoulder and Hand Score (DASH). Complications and revision surgeries were also analyzed. Results. The extension-flexion arc was $111^{\circ}$ for primary and $96^{\circ}$ for secondary TEA $(p=0.14)$. Both MEPS ( 94 vs. 79 points, $p=0.051)$ and DASH (24 vs. 48 points, $p=0.007$ ) showed favorable results for primary TEA. Pain was described as moderate or severe by $11 \%$ of patients after primary TEA and $36 \%$ after secondary TEA. The duration of surgery was significantly longer for secondary TEA (91 vs. $150 \mathrm{~min}, p=0.002$ ). One patient in the primary group had septic loosening of the prosthesis. In the secondary TEA group, two cases of aseptic loosening were documented. Conclusion. Primary TEA showed favorable functional results over secondary TEA. Notably, subjective evaluation was better in the primary TEA group owing to less pain than in the secondary TEA group. Despite the extended duration of surgery for secondary TEA, the complication rates were comparable. Level of evidence. III.

Keywords

Elbow - Surgery · Postoperative complications. Pain · Prosthesis

\section{Primäre vs. sekundäre totale Ellenbogenarthroplastik bei distaler Humerusfraktur. Klinische Ergebnisse einer retrospektiven Fall-Kontroll-Studie}

\section{Zusammenfassung}

Hintergrund. Ziel dieser Studie war es, die klinischen Ergebnisse und Komplikationen nach primärer Ellenbogenprothese (primäre Totalendoprothese, TEP) und Ellenbogenprothese nach Versagen einer Rekonstruktion oder konservativen Therapie (sekundäre TEP) in der Behandlung distaler Humerusfrakturen zu vergleichen. Es wurde davon ausgegangen, dass die primäre Ellenbogenprothese bessere klinische und funktionelle Ergebnisse bei niedrigerer Komplikationsrate aufweist. Material und Methode. Die Daten von 23 Patienten (primäre TEP: $n=9$; sekundäre TEP: $n=14$; Alter: 66 Jahre) wurden retrospektiv in die Studie eingeschlossen und nach durchschnittlich 28 (6-43) Monaten einmalig nachuntersucht. Die klinischen und funktionellen Ergebnisse wurden anhand des Bewegungsumfangs, Mayo Elbow Performance Score (MEPS) und Disabilities of the Arm, Shoulder and Hand Score (DASH) beurteilt. Komplikationen und Revisionseingriffe wurden ausgewertet. Ergebnisse. Der Bewegungsumfang für Extension - Flexion betrug $111^{\circ}$ nach primärer TEP und $96^{\circ}$ nach sekundärer TEP $(p=0,14)$. Sowohl der MEPS (94 vs. 79 Punkte, $p=0,051$ ) als auch der DASH ( 24 vs. 48 Punkte, $p=0,007$ ) zeigten bessere Ergebnisse für die primäre TEP. Das Ausmaß der Schmerzen wurde als moderat oder hoch von $11 \%$ der Patienten nach primärer und $36 \%$ der Patienten nach sekundärer TEP angegeben. Die Op.-Dauer war signifikant länger für sekundäre TEPImplantationen (91 vs. $150 \mathrm{~min}, p=0,002$ ). Bei einem Patienten bestand eine septische
Lockerung nach primärer TEP. Eine aseptische Lockerung war bei 2 Patienten nach sekundärer TEP dokumentiert.

Schlussfolgerung. Die primäre Ellenbogenprothese erzielt bessere funktionelle Ergebnisse im Vergleich zu sekundären TEP. Insbesondere die geringere Schmerzsituation nach primärer Ellenbogen-TEP ist ein Grund für die besseren subjektiven Ergebnisse. Trotz längerer Op.-Dauer für die sekundäre TEP waren die Komplikationsraten vergleichbar. Evidenzlevel. III.

Schlüsselwörter

Ellenbogen - Chirurgie - Postoperative Komplikationen · Schmerzen · Prothese

\section{Results}

\section{Baseline data}

Of 35 patients who met the inclusion criteria, six died from unrelated causes. After losing six patients to follow-up, 23 patients finally participated in the study (follow-up rate, 79\%; mean follow-up, 28 months; range, 6-47 months; mean age, 66 years; range, $41-85$ years). Nine of the 23 patients (39\%; mean age:
70 years; 8 women) underwent treatment with primary TEA. The remaining 14 patients (61\%; mean age: 63 years; 11 women) underwent secondary TEA implantation. Secondary TEA implantation resulted after loss of reduction following double-plate osteosynthesis in four patients, nonunion in two (one after reconstruction and one after nonoperative therapy), nonunion with an additional partial necrosis of the distal humerus in a further three, posttrau- matic arthritis after internal fixation in two, and posttraumatic arthritis after nonoperative treatment in three patients. After initial joint-preserving therapy, we observed two peaks regarding the time between trauma and secondary TEA implantation. The mean time between trauma and TEA was $227 \pm 226$ days (range, 14-760) for failed internal fixation, nonunion, partial necrosis, or posttraumatic elbow arthritis after reconstruction. Patients with arthritis 


\begin{tabular}{|c|c|c|c|}
\hline Characteristics & Total & Primary TEA & Secondary TEA \\
\hline Number of patients & 23 & 9 & 14 \\
\hline $\begin{array}{l}\text { Mean follow-up } \\
\text { (months) }\end{array}$ & $28 \pm 16(6-73)$ & $22 \pm 12(6-41)$ & $32 \pm 18(8-73)$ \\
\hline Mean age (years) & $66 \pm 12(41-85)$ & $70 \pm 13(41-85)$ & $63 \pm 10(44-82)$ \\
\hline Male:female & $4: 19$ & $1: 8$ & $3: 11$ \\
\hline \multicolumn{4}{|c|}{ AO classification, distal humerus } \\
\hline - Type A fracture & 1 & 0 & 1 \\
\hline - Type B fracture & 2 & 0 & 2 \\
\hline - Type C fracture & 20 & 9 & 11 \\
\hline
\end{tabular}

after nonoperative treatment required TEA on average $29 \pm 7.8$ years (range, 20-35) after trauma. Further baseline information is listed in $\bullet$ Table 1.

Regarding primary TEA, two patients were initially treated with an external fixator on the day of trauma. The indication was a damage-control strategy because of critical soft-tissue swelling or a traumatic irritation of the ulnar and radial nerve. While all nine primary TEA implants were performed without removal or replacement of the radial head, the radial head was resected in seven patients with secondary TEA. In addition to the secondary TEA implantation, the initially inserted internal fixation had to be removed in all ten cases during the same surgery. Therefore, the duration of surgery for secondary TEA was significantly longer than for primary TEA $(p=0.007)$. While patients after primary TEA were hospitalized on average for 18 days, patients with secondary TEA were discharged after 17 days $(p=0.57)$.

\section{Complications}

At the time of the final follow-up, three minor complications and one major complication after primary TEA were recorded (- Table 2). An 81-year-old woman suffered an infection of the operated elbow with septic loosening of the prosthesis 1 month after implantation, and the prosthesis had to be removed. While treating the infection, the elbow was stabilized with an external fixator. One month later, the infection was dominated and the elbow was arthrodesed in $90^{\circ}$ flexion. A rotation of the forearm with supination/pronation of $60 / 0 / 90^{\circ}$ was still possible. Because of the limited range of motion and persisting moderate pain, the patient was dissatisfied with the result. Objective and subjective scores confirmed the poor outcome (MEPS: 30 points; DASH: 88 points). Since the poor functional result was due to a change in therapy with consecutive loss of extension and flexion in the elbow, this patient was not considered in the comparison of the functional results, but in the complication analysis.

Regarding secondary TEA, there were seven patients with minor and four patients with major complications (- Table 2). Two patients required complication-related revision, both due to an aseptic loosening. A 50-year-old woman had to undergo revision 21 months after TEA. The ulnar and humeral component had loosened without any signs of infection. Both components were replaced. A 56-year-old woman initially suffered an aseptic loosening of the ulnar component with replacement of the same after 10 months. After another 10 months, the ulnar and humeral components had loosened and both were replaced. Two patients suffered a periprosthetic fracture after a renewed trauma of the elbow. Both were stabilized with additional locked plating.

Summarizing major complications, one out of nine patients with primary and four out of 14 patients $(2 \times$ endogenous and $2 \times$ traumatic causes) with secondary TEA suffered a major complication $(p=0.47)$.

Four patients with primary TEA had a follow-up radiograph within a mean of 5.8 \pm 5.9 months (range, 1-13). Three patients showed a proper integration of the wedged ventral bone graft without any signs of TEA loosening. Even the patient with the postoperative infection did not show definite signs of loosening, although the humeral and ulnar component were loose intraoperatively. After secondary TEA, one postoperative radiograph showed cement passed up to neck of the proximal humerus. Seven patients had a follow-up radiograph within a mean of $16 \pm 14$ months (range, 3-47). Five patients showed a proper integration of the wedged ventral bone graft without any signs of TEA loosening. In one patient, signs of humeral and ulnar loosening were seen after 20 months. Another patient showed radiological signs of loosening of the ulnar component after 10 months. After another 9 months after revision with replacement of the ulnar component, again signs of humeral and ulnar loosening were seen. An infection was excluded intraoperatively in both patients.

\section{Clinical outcome measures}

Comparing the clinical outcome measures between primary and secondary TEA, the mean extension/flexion arcs after primary and secondary TEA were $111^{\circ}$ and $96^{\circ}$, respectively $(p=0.14)$. The MEPS (94 vs. 70 points, $p=0.051$ ) and DASH score (26 vs. 48 points, $p=0.007$ ) showed better results for primary TEA than for secondary TEA. In the primary group, one out of nine patients complained about moderate or severe pain. For the secondary group, five out of 14 patients reported moderate or severe pain (- Table 3).

Upon analyzing the poorer results for secondary TEA, this group was divided into early secondary TEA (TEA within 6 months of trauma) and late secondary TEA (TEA later than 6 months after trauma). Six patients had TEA implantation within 6 months. The mean time between trauma and TEA implantation was 74 days (range, 14-147). Eight patients had TEA implantation later than 6 months (147 months; range, 6-489). While the range of motion between both of these groups showed no marked dif- 
Table 2 Patient data for primary and secondary TEA

\begin{tabular}{|c|c|c|c|c|c|c|c|c|c|c|c|}
\hline & Age & Sex & Prim. treat. & $F / U$ & $\begin{array}{l}\text { Time to TEA } \\
\text { (days) }\end{array}$ & $\begin{array}{l}\text { ROM } \\
\left({ }^{\circ}\right)\end{array}$ & MEPS & DASH & Pain & Complication & $\begin{array}{l}\text { Rad. loosening } \\
\text { (months) }\end{array}$ \\
\hline \multicolumn{12}{|c|}{ Primary } \\
\hline $1^{a}$ & 81 & $\mathrm{~F}$ & - & 41 & 4 & 0 & 30 & 87 & Mild & Septic loosening & No (1) \\
\hline $2^{\mathrm{a}}$ & 74 & $\mathrm{~F}$ & - & 18 & 4 & 130 & 100 & 25 & Moderate & - & - \\
\hline $3^{a}$ & 62 & $\mathrm{~F}$ & - & 39 & 7 & 115 & 80 & 34 & None & - & No (8) \\
\hline $4^{\mathrm{a}}$ & 74 & $\mathrm{~F}$ & - & 13 & 8 & 110 & 95 & 33 & Mild & - & - \\
\hline $5^{\mathrm{a}}$ & 85 & $\mathrm{~F}$ & - & 6 & 9 & 100 & 100 & 12 & None & - & - \\
\hline $6^{\mathrm{a}}$ & 76 & $\mathrm{~F}$ & - & 28 & 5 & 100 & 100 & 14 & None & Irritation ulnar nerve & - \\
\hline $7^{\mathrm{a}}$ & 65 & M & - & 29 & 6 & 90 & 75 & 43 & None & $\begin{array}{l}\text { (Posttraumatic irritation } \\
\text { ulnar and radial nerve) }\end{array}$ & - \\
\hline $8^{\mathrm{a}}$ & 75 & $\mathrm{~F}$ & - & 15 & 4 & 125 & 100 & 19 & None & - & No (1) \\
\hline $9^{a}$ & 41 & $\mathrm{~F}$ & - & 13 & 10 & 115 & 100 & 8 & None & Irritation ulnar nerve & No (13) \\
\hline \multicolumn{12}{|c|}{ Secondary } \\
\hline $1^{\mathrm{a}}$ & 68 & M & ORIF & 20 & 335 & 50 & 25 & 76 & Severe & $\begin{array}{l}\text { Postoperative } \\
\text { hematoma }\end{array}$ & No (10) \\
\hline $2^{a}$ & 68 & $\mathrm{~F}$ & ORIF & 47 & 206 & 90 & 80 & 33 & Mild & - & - \\
\hline $3^{a}$ & 67 & $\mathrm{~F}$ & ORIF & 22 & 147 & 110 & 80 & 42 & Mild & - & - \\
\hline $4^{a}$ & 82 & $\mathrm{~F}$ & ORIF & 24 & 14 & 70 & 95 & 43 & None & - & - \\
\hline $5^{\mathrm{a}}$ & 64 & M & ORIF & 8 & 17 & 80 & 90 & 28 & None & (Periprosthetic fracture) & No (19) \\
\hline 6 & 70 & $\mathrm{~F}$ & ORIF & 43 & 26 & 110 & 100 & 20 & None & Irritation ulnar nerve & - \\
\hline 7 & 50 & $\mathrm{~F}$ & ORIF & 36 & 443 & 130 & 70 & 65 & Moderate & Aseptic loosening & Humeral + ulnar (20) \\
\hline 8 & 44 & $\mathrm{~F}$ & ORIF & 44 & 760 & 130 & 85 & 54 & Mild & - & - \\
\hline 9 & 59 & $\mathrm{~F}$ & ORIF & 9 & 310 & 100 & 75 & 68 & Severe & $\begin{array}{l}\text { Irritation ulnar nerve, } \\
\text { (periprosthetic fracture) }\end{array}$ & No (8) \\
\hline 10 & 61 & $\mathrm{~F}$ & ORIF & 14 & 143 & 80 & 80 & 51 & Mild & Irritation ulnar nerve & No (47) \\
\hline 11 & 76 & $\mathrm{~F}$ & Conservative & 27 & 20.8 years & 110 & 100 & 21 & None & Irritation ulnar nerve & - \\
\hline 12 & 62 & M & Conservative & 40 & 31.3 years & 95 & 65 & 69 & Moderate & Irritation ulnar nerve & No (3) \\
\hline 13 & 57 & $\mathrm{~F}$ & Conservative & 44 & 94 & 115 & 100 & 35 & None & - & - \\
\hline 14 & 51 & $\mathrm{~F}$ & Conservative & 73 & 35.6 years & 70 & 55 & 70 & Moderate & $\begin{array}{l}\text { Irritation ulnar nerve, } \\
\text { aseptic loosening }(2 \times)\end{array}$ & $\begin{array}{l}\text { Ulnar (10); } \\
\text { humeral + ulnar (9) }\end{array}$ \\
\hline
\end{tabular}

ference (early secondary TEA: $94^{\circ}$; late secondary TEA: $97^{\circ}$ ), significantly better MEPS results were seen for patients with TEA implantation within 6 months of trauma (early secondary TEA: 90 points; late secondary TEA: 69 points; $p=0.046$ ).

No significant differences in the clinical and functional results were found upon comparing secondary TEA after operative and nonoperative treatment. The extension-flexion arc was $95^{\circ}$ vs. $98^{\circ}$, MEPS was 78 vs. 80 points, and the DASH score was 48 vs. 49 points, respectively.

\section{Discussion}

The purpose of this study was to compare clinical and functional results after primary TEA and TEA after failed osteosynthesis or conservative treatment for patients with distal humerus fractures. Primary TEA yielded favorable functional results according to range of motion and MEPS compared with secondary TEA. The DASH score also showed significantly better results for primary TEA. Since pain values were higher after secondaryTEA and the DASH score as a subjective parameter is influenced by the pain situation of the patient, this might explain the better DASH values for the primary TEA group. The duration of surgery for secondary TEA was significantly longer, since most of the patients required an additional implant removal; however, this did not influence the rate of major complications. Although the patient groups were small (six vs. eight patients), when analyzing the poorer results for secondary TEA, MEPS yielded better results if TEA implantation was performed within 6 months.

In 1997, the first data regarding the treatment of distal humerus fractures by TEA in the elderly were published [8]. The results of 21 primary TEAs were retrospectively reviewed with a mean follow-up of 3.3 years. On the basis of the 


\begin{tabular}{|c|c|c|c|}
\hline & Primary & Secondary & $p$ \\
\hline Range of motion $\left({ }^{\circ}\right)$ & $111^{\circ} \pm 13\left(90^{\circ}-130^{\circ}\right)$ & $96^{\circ} \pm 24\left(50^{\circ}-130^{\circ}\right)$ & 0.14 \\
\hline MEPS & $94 \pm 10(75-100)$ & $79 \pm 21(25-100)$ & 0.051 \\
\hline DASH & $24 \pm 12(8-43)$ & $48 \pm 19(20-76)$ & $0.007^{*}$ \\
\hline Satisfaction & 8 out of $9(89 \%)$ & 10 out of $14(71 \%)$ & 0.32 \\
\hline $\begin{array}{l}\text { Pain (moderate/ } \\
\text { severe) }\end{array}$ & 1 out of $9(11 \%)$ & 5 out of $14(36 \%)$ & 0.19 \\
\hline
\end{tabular}

MEPS, 15 elbows were deemed to have an excellent result and five a good result. The mean arc of motion was $105^{\circ}$, and all patients were satisfied with their functional outcome. The authors concluded TEA is an alternative treatment in severely comminuted fractures of the distal humerus in elderly patients. However, they reported that this procedure was not an alternative to osteosynthesis in younger patients.

In 2004, this study was updated [9], when 43 fractures were retrospectively reviewed with an average follow-up of 7 years. The mean arc of flexion was $24^{\circ}-131^{\circ}$. The MEPS averaged 93 points with $93 \%$ good or excellent results. Of the patients, $14(29 \%)$ had one complication and three (6\%) had two complications. In total, ten additional operations were required, five of which were related to the soft tissue and five to the implant or bone. Five revision arthroplasties were required: one for septic loosening, one for aseptic loosening, and three for periprosthetic fractures.

In 2013, the largest study comprising 87 TEAs for acute distal humerus fractures was published [6]. After a mean follow-up of 37.5 months, the MEPS was reported to be 86 points and the quick DASH 24 points. The mean extension/flexion arc was $97^{\circ} ; 87 \%$ of the patients presented no or minimal pain. Complications occurred in 20 patients (23\%): seven neurological injuries, five hematomas, two complex regional pain syndromes (CRPS), one deep infection, and one skin necrosis. Surgical revision was necessary in eight cases (9\%) including one additional internal fixation for a periprosthetic fracture and one for fracture of the humeral stem. Two prostheses had loosened, and one was replaced. The ideal patient for primary TEA was proposed to be an 80-yearold subject without any comorbidities and a history of inflammatory arthritis and osteoporosis, presenting with a comminuted fracture.

Mighell et al. reported on 28 cases of TEA after failed fixation with a 3-year follow-up [22]. The clinical results were improved, but $21 \%$ of patients $(6 / 28)$ required revision surgery: five due to aseptic loosening and one arthrodesis because of septic loosening.

Comparing early versus delayed TEA, Prasad and Dent reported on 32 patients with a follow-up of 56 months [23]. The early group $(n=15)$ with acute fractures attained a flexion arc from $26^{\circ}$ to $119^{\circ}$. The MEPS was 85 points, and $85 \%$ had a good or excellent result. The delayed group $(n=17)$ after internal fixation or nonoperative treatment attained a flexion arc from $32^{\circ}$ to $120^{\circ}$. The MEPS was 80 points with $79 \%$ good or excellent results. Neither range of motion nor MEPS showed any statistically significant difference in both groups; even the subjective satisfaction was similar. Two patients in the early group (13\%) and five in the delayed group (29\%) experienced a complication. The early group had one case of CRPS after preoperative ulnar nerve damage and one case of aseptic loosening, which required revision. In the delayed group there were two cases of postoperative ulnar nerve palsy. One patient developed a CRPS and subsequently presented with a deep infection requiring removal of the TEA. One patient suffered a mild heterotopic ossification, one a superficial infection, and one an aseptic loosening with revision of the arthroplasty.

In contrast to the aforementioned study, our data showed better functional results for primary TEA. The subjective result regarding the DASH score was significantly better. With a bigger patient population, which would probably have raised the power of this study, even the MEPS $(p=0.051)$ could have reached a significant level. The better results for primary arthroplasty correspond to results in the literature on other joints such as the shoulder, where secondary arthroplasty, although improving the clinical status of the patient, does not yield similar results as those achieved with primary arthroplasty $[24,25]$.

\section{Study limitations}

The limitations of our study include the retrospective design and small number of patients, which is comparable to previous studies but might have underpowered the study. Although a radiological evaluation was performed, the follow-up was shorter than the clinical follow-up and radiographs were only available for 11 of 23 patients (47\%). Furthermore, a mean follow-up of only 28 months is not sufficient for presenting long-term results and complications after TEA.

\section{Practical conclusion}

\footnotetext{
- Fracture reconstruction remains the treatment of choice owing to the lifelong limitation of weight-bearing of up to $5 \mathrm{~kg}$. Besides, revision options are limited and can result-as seen in our case-in a complete loss of elbow function.

- Since 10- and 20-year survival rates after TEA are $81 \%$ and $61 \%$, respectively, which is poorer than for knee and hip arthroplasty, this should also be considered when indicating TEA [26].

- However, in view of a poor result after reconstruction, primary TEA should be recommended to elderly or selected patients, as TEA yielded better functional results with less pain than secondary TEA.
} 


\section{- If complications appear after recon- struction, early revision to TEA should be recommended, because late con- version leads to poorer results. \\ - Although secondary TEA requires implant removal in most cases, which can be challenging and extends the operating time considerably, there is no significant difference in the rate of major complications.}

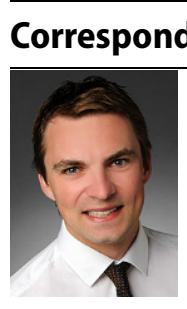

Dr. Alexander Ellwein

Department for Orthopaedic Surgery, Medical School Hannover, DIAKOVERE

Annastift

Anna-von-Borries-Straße 1-7, 30625 Hannover, Germany alexander.ellwein@ diakovere.de

\section{Compliance with ethical guidelines}

Conflict of interest H. Lill and T. Smith are consultants for DepuySynthes. A. Ellwein, C. Voigt, J. Imrecke and J.C. Katthagen declare that they have no competing interests.

The study protocol was approved by the local ethics committee of Medizinische Hochschule Hannover (Nr. 1667-2012) and complied with the principles of the Declaration of Helsinki.

Open Access. This article is distributed under the terms of the Creative Commons Attribution 4.0 International License (http://creativecommons.org/licenses/by/ 4.0/), which permits unrestricted use, distribution, and reproduction in any medium, provided you give appropriate credit to the original author(s) and the source, provide a link to the Creative Commons license, and indicate if changes were made.

\section{References}

1. Triplet JJ, Kurowicki J, Momoh E et al (2016) Trends in total elbow arthroplasty in the Medicare population: a nationwide study of records from 2005 to 2012. JShoulderElbow Surg 25:1848-1853

2. Gay DM, Lyman S, Do H et al (2012) Indications and reoperation rates for total elbow arthroplasty: an analysis of trends in New York State. J Bone Joint Surg Am 94:110-117

3. Day JS, Lau E, Ong KL et al (2010) Prevalence and projections of total shoulder and elbow arthroplasty in the United States to 2015. JShoulder Elbow Surg 19:1115-1120

4. Toulemonde J, Ancelin D, Azoulay V et al (2016) Complications and revisions after semiconstrained total elbow arthroplasty: a mono- centre analysis of one hundred cases. Int Orthop 40:73-80

5. Voloshin I, Schippert DW, Kakar S et al (2011) Complications of total elbow replacement: a systematic review. J Shoulder Elbow Surg 20:158-168

6. Mansat $P$, Nouaille Degorce $H$, Bonnevialle $N$ et al (2013) Total elbow arthroplasty for acute distal humeral fractures in patients over 65 years old-results of a multicenter study in 87 patients. Orthop Traumatol Surg Res 99:779-784

7. Ducrot G, Ehlinger M, Adam P et al (2013) Complex fractures of the distal humerus in the elderly: is primary total elbow arthroplasty a valid treatment alternative? A series of 20 cases. Orthop Traumatol Surg Res 99:10-20

8. CobbTK,MorreyBF (1997)Totalelbowarthroplasty as primary treatment for distal humeral fractures in elderly patients. JBone Joint Surg Am 79:826-832

9. Kamineni S, Morrey BF (2004) Distal humeral fractures treated with noncustom total elbow replacement. JBone Joint Surg Am 86-A:940-947

10. Augereau B, Mansat P (2005) Total elbow arthroplasties. Rev Chir Orthop Reparatrice Appar Mot 91(Supp. 5):2S31-2S96

11. Charissoux J-L, Mabit C, Fourastier J et al (2008) Comminuted intra-articular fractures of the distal humerus in elderly patients. Rev Chir Orthop Reparatrice Appar Mot 94:36-62

12. Gambirasio R, Riand N, Stern R, Hoffmeyer P (2001) Total elbow replacement for complex fractures of the distal humerus. An option for the elderly patient. J Bone Joint Surg Br 83:974-978

13. Ray PS, Kakarlapudi K, Rajsekhar C, Bhamra MS (2000) Total elbow arthroplasty as primary treatment for distal humeral fractures in elderly patients. Injury 31:687-692

14. Garcia J, Mykula R, Stanley D (2002) Complex fractures of the distal humerus in the elderly. The role of total elbow replacement as primary treatment. J Bone Joint Surg Br 84:812-816

15. Zalavras CG, Vercillo MT, Jun B-J et al (2011) Biomechanical evaluation of parallel versus orthogonal plate fixation of intra-articular distal humerus fractures. J Shoulder Elbow Surg 20:12-20

16. Lee KT, Lai CH, Singh S (2006) Results of total elbow Arthroplasty in the treatment of distal humerus fractures in elderly asian patients. J Trauma 61:889-892

17. Plaschke HC, Thillemann TM, Brorson S, Olsen BS (2014) Implant survival after total elbow arthroplasty: a retrospective study of 324 procedures performed from 1980 to 2008 . JShoulderElbow Surg 23:829-836

18. Ellwein A, Lill H, Voigt C et al (2015) Arthroplasty compared to internal fixation by locking plate osteosynthesis in comminuted fractures of the distal humerus. Int Orthop 39:747-754

19. Oestern HJ, Tscherne H (1983) Pathophysiology and classification of soft tissue damage in fractures. Orthopade 12:2-8

20. Hackl M, Leschinger T, Uschok $S$ et al (2017) Rehabilitation of elbow fractures and dislocations. Obere Extremität 12:201-207

21. LeschingerT,Müller LP,HackIM, WegmannK(2016) Techniques for arthrolysis of the elbow. Obere Extremität 11:149-158

22. Mighell M, Virani M, Frankle M (2006) Failed open reduction and internal fixation for elbow fractures converted to total elbow arthroplasty. American shoulder and elbow surgeons closed meeting, Chicago, IL, pe52
23. Prasad N, Dent C (2008) Outcome of total elbow replacement for distal humeral fractures in the elderly: a comparison of primary surgery and surgeryafterfailed internal fixation or conservative treatment. J Bone Joint Surg Br 90:343-348

24. Schliemann B, Theisen C, BarzLetal(2016) Revision osteosynthesis vs. prosthesis after unsuccessful humeral head osteosynthesis. Obere Extremität 11:239-247

25. Sebastia-Forcada E, Lizaur-Utrilla A, CebrianGomez R et al (2017) Outcomes of reverse total shoulder arthroplasty for proximal humeral fractures: primary arthroplasty versus secondary arthroplasty following failed proximal humeral locking plate fixation. J Orthop Trauma 31:e236-e240

26. Krukhaug Y, Hallan G, Dybvik E et al (2018) A survivorship study of 838 total elbow replacements: a report from the Norwegian Arthroplasty Register 1994-2016. JShoulder Elbow Surg 27:260-269 